\title{
Estudo descritivo de acidentes de trabalho envolvendo trabalhadores florestais no Estado de Minas Gerais
}

\author{
Hugo Ferney Martínez PATIÑO수, Ângelo Márcio Pinto LEITEE ${ }^{1}$, Marcio Leles Romarco OLIVEIRA ${ }^{1}$, \\ Stanley SCHETTINO2, Mariana Roberta Lopes SIMÕES ${ }^{1}$
}

\author{
${ }^{1}$ Universidade Federal dos Vales do Jequitinhonha e Mucuri, Diamantina, MG, Brasil. \\ ${ }^{2}$ Instituto de Ciências Agrárias, Universidade Federal de Minas Gerais, Montes Claros, MG, Brasil. \\ *E-mail: schettino@ufmg.br \\ (ORCID: 0000-0001-8746-303X; 0000-0002-5516-0613; 0000-0002-8097-1135; 0000-0001-8085-1910; 0000-0003-0543-6906)
}

Recebido em 21/05/2021; Aceito em 20/09/2021; Publicado em 24/09/2021.

\begin{abstract}
RESUMO: As atividades florestais são reconhecidas por expor os trabalhadores à agentes de risco, gerando incapacidades que dificultam o acesso e continuidade de atuação no mercado de trabalho. Nesse sentido, estudou-se com esta pesquisa os diferentes parâmetros registrados no banco de dados do Ministério da Previdência Social referentes às Comunicações de Acidentes de Trabalho - (CATs), com ênfase no setor florestal de Minas Gerais no período entre 2011 e 2017. Objetivou-se avaliar os dados de acidentes de trabalho com o intuito de gerar conhecimento referente aos agentes causadores, como os danos na saúde dos trabalhadores e suas repercussões. Verificou-se que os principais agentes causadores de acidentes foram: manuseio de madeira, condições do terreno, ferramentas com ou sem força motriz e veículos. As lesões foram responsáveis por $93,9 \%$ dos registros, dos quais $49,5 \%$ ocasionaram fraturas, comprometendo principalmente os membros inferiores e superiores dos trabalhadores. Portanto, as atividades florestais expõem os trabalhadores a riscos que geram como consequência acidentes, resultando muitas vezes em incapacidades no desenvolvimento das atividades laborais requeridas, e assim, dificultando o acesso ao mercado de trabalho.
\end{abstract}

Palavras-chave: segurança no trabalho; trabalho florestal; saúde do trabalhador florestal.

\section{Descriptive study of work accidents involving forest workers at Minas Gerais State}

\begin{abstract}
Forestry activities are recognized for exposing workers to risk agents, generating disabilities that hinder the access and continuity of work of the people affected in the labor market. In this sense, it was studied with this research the different parameters registered in the database of the Ministry of Social Security referring to the Communication of Accidents at Work - CATs, with emphasis on the forestry sector of Minas Gerais, at the period between 2011 and 2017. The objective was to evaluate the data on accidents at work in order to generate knowledge regarding the causative agents, as the damage to workers' health and their repercussions. It was found that the main causative agents of accidents were: handling of wood, conditions of the ground, tools with or without driving force and vehicles. The injuries were responsible for $93.9 \%$ of the records, of which $49.5 \%$ caused fractures, mainly affecting the workers' lower and upper limbs. Therefore, forestry activities expose workers to risks that result in accidents, often resulting in disabilities in the development of the required work activities and, thus or hindering their access to the labor market.
\end{abstract}

Keywords: work safety; forestry work; forest workers' health.

\section{INTRODUÇÃO}

No Brasil, o setor florestal apresentou uma área total plantada com cerca de 8 milhões de hectares, ocupada principalmente com eucalipto e pinus. Este segmento gerou uma arrecadação tributária de $\mathrm{R} \$ 71,1$ bilhões, empregando 510 mil pessoas diretamente e 3,19 milhões indiretamente. Estima-se que o setor brasileiro de árvores plantadas tenha gerado $\mathrm{R} \$ 10$ bilhões de renda aos trabalhadores anualmente, onde desse total, aproximadamente $\mathrm{R} \$ 9$ bilhões foram destinados ao consumo das famílias e o restante à poupança nacional (Industria Brasileira de Árvores - IBÁ, 2021).

As plantações de eucalipto e pinus cobrem uma extensão de 5,7 milhões e 1,6 milhões de hectares respectivamente. Sendo Minas Gerais o maior produtor de florestas plantadas de eucalipto do país com $24 \%$ do total, seguido de São Paulo com $17 \%$ e Mato Grosso do Sul com 15\%. No caso do pinus as plantações estão localizadas principalmente na região sul, nos estados do Paraná e Santa Catarina (IBÁ, 2021).

De maneira geral, o setor apresenta diversos estágios de desenvolvimento e níveis tecnológicos. O que torna bastante complexo o estudo e entendimento das diferentes relações e fatores correlacionados com as atividades florestais, as quais envolvem invariavelmente a interação homem, máquina, ambiente e organização do trabalho.

Existem uma série de doenças e riscos profissionais ligadas aos trabalhadores da indústria florestal, devido à interação com agentes físicos como calor e frio, muitas vezes em virtude das condições climáticas extremas. As vibrações são outro fator que podem ocasionar grande variedades de desconfortos, tais como: dor lombar, degeneração dos sistemas vascular, neurológico, ósseo-articular e muscular 
como é o caso da doença dos dedos brancos (SUCHOMEL et al., 2011). Já os agentes mecânicos, como ferramentas manuais e máquinas, são com frequência causadores de cortes, fraturas e amputações. Outros problemas comuns são o desenvolvimento de doenças osteomusculares, principalmente devido à adoção de posturas forçadas, movimentos repetitivos e manuseio de cargas pesadas.

Devido ao anteriormente exposto, é de supor que o setor florestal requer alta demanda de esforço, tanto das atividades manuais, quanto das semimecanizadas e mecanizadas. Essas atividades podem causar sobrecargas aos trabalhadores devido as altas exigências de força, fator que promove a fadiga física e mental, além da redução na concentração, diminuição nos rendimentos, indução aos erros, etc. Tudo isso se traduz em um maior risco de acidentes de trabalho, e ao longo prazo, o desenvolvimento de doenças associadas ao trabalho.

Os acidentes de trabalho devem ser entendidos como um indicador dos elementos no ambiente de trabalho que têm manifestações deficientes ou negativas, não sendo, portanto, acontecimentos isolados que ocorrem por acaso. Assim, seu estudo minucioso poderá reconhecer que os acidentes de trabalho e as doenças profissionais são "fenômenos socialmente determinados, relacionados aos fatores de risco presentes no sistema de produção”. E que estes, por sua vez, são resultado de erros na engenharia de projetos e, ou, na má gestão e desacato às normas estabelecidas, não tomando em consideração o acaso como elemento influenciador (Ministério do Trabalho e Emprego - MTE, 2010).

Assim, os acidentes de trabalho são resultado da intensidade e do tempo de exposição a situações de risco, podendo resultar em lesões não fatais ou fatais. As doenças profissionais são contraídas em consequência da exposição aos fatores de risco provenientes de uma atividade desenvolvida, diferindo dos acidentes de trabalho por estarem relacionados a eventos acumulativos.

Embora a palavra "acidente" sugira que os mesmos são produto do acaso, a maioria dos eventos adversos é previsível e pode ser prevenido. Portanto, corrobora-se a importância do estudo minucioso dessas ocorrências, uma vez que os acidentes de trabalho e as doenças profissionais são causados por atos inseguros, condições inseguras ou os dois fatores em conjunto, além do fator pessoal de insegurança (Associação Brasileira de Normas Técnicas - ABNT, 2001; CANTO et al., 2007).

Os atos inseguros são as atitudes (ação, omissão, imperícia, imprudência ou negligência) do trabalhador que contrariam as normas de segurança. Por sua vez, as condições inseguras referem-se aquelas do meio ambiente de trabalho capazes de oferecer riscos aos trabalhadores. Os acidentes geralmente resultam das interações inadequadas entre $O$ homem, a tarefa e o seu ambiente (IIDA; GUIMARÃES, 2016).

De acordo com o Ministério do Trabalho e Emprego MTE (2010), o objetivo da prevenção é saber o que acontece no ambiente, e a probabilidade de eventos adversos ocorrerem num sistema produtivo qualquer. Esse conhecimento, junto com as análises dos eventos apresentados, visa gerar políticas, programas e projetos nos quais o objetivo principal é proteger as pessoas e os bens da organização e dessa forma, ampliando as possibilidades de prevenção.

A identificação dos fatores de risco permite a adoção de medidas de controle para eliminá-los e, ou reduzi-los, se a alternativa anterior não for possível. Mas, "a ocorrência de um evento adverso indica que as medidas de controle de risco foram inadequadas ou insuficientes" (MTE, 2010). Ocasionando perdas para os trabalhadores acidentados e suas famílias, perdas para a empresa que terão custos ocultos como absentismo, perdas de tempo e perdas de produção, e também afetando de forma negativa a sociedade.

Segundo a Agência Europeia de Segurança e Saúde no Trabalho - EU-OSHA (2008), o trabalho florestal é considerado de alto risco por apresentar altas taxas de fatalidades e de ferimentos, em comparação com outros setores econômicos. As causas mais comuns de acidentes fatais são: queda de árvores, acidentes com veículos e acidentes com as máquinas e equipamentos. Enquanto acidentes não fatais são comuns pela queda de galhos das árvores, escorregamentos causados pelas condições do terreno, e também por acidentes com os equipamentos.

Neste contexto, este trabalho objetivou avaliar as informações associadas aos acidentes dos trabalhadores florestais registrados nas Comunicações de Acidente de Trabalho (CAT) do Estado de Minas Gerais, no período de 2011 a 2017, com o intuito de gerar conhecimento referente aos agentes causadores, repercussões e danos na saúde dos trabalhadores de atividades florestais.

\section{MATERIAL E MÉTODOS}

Para o levantamento dos dados foram consultadas as informações contidas no banco de dados da Diretoria de Saúde do Trabalho do Instituto Nacional do Seguro Social DIRSAT/INSS. O delineamento da pesquisa foi do tipo documental como definido por Gil (2008), sendo esta desenvolvida a partir de materiais/dados que não receberam ainda um tratamento analítico ou, então, que pudessem ser reestruturados para atender aos objetivos da pesquisa.

\subsection{Análise de dados}

Para a análise dos dados de interesse, utilizou-se as informações dos CAT, segundo a Classificação Nacional de Atividades Econômicas - CNAE. Onde abrangeu-se o período de 01/01/2011 até 31/12/2017 para o Estado de Minas Gerais. As variáveis coletadas corresponderam a: CNAE, Sexo, Data do Acidente, Idade do Acidentado, Estado Civil do Segurado, Classificação Brasileira de Ocupações - CBO, Valor de Remuneração do Segurado, Classificação Internacional de Doenças - CID-10, Tipo do Acidente, Agente Causador do Acidente, Parte do Corpo Atingida, Natureza da Lesão, Situação Geradora do Acidente, Indicação de Óbito e Município do Segurado.

Para a análise dos dados, foi utilizada a estatística descritiva por intermédio de métodos gráficos e tabelas. Utilizando o software $\mathrm{R}$ (versão 3.3.3) como principal ferramenta de apresentação dos resultados.

\subsection{Classificação Nacional de Atividades Econômicas (CNAE)}

A CNAE é um código oficialmente adotado pelo Sistema Estatístico Nacional, cujo principal objetivo é a classificação padronizada das atividades econômicas exercidas por empresas, para a disseminação de informações e divulgação de estatísticas de cunho econômicas e socioeconômicas (Instituto Brasileiro de Geografia e Estatística - IBGE, 2007).

Nesta pesquisa, para o levantamento dos CAT foram solicitados os códigos referentes às atividades da Seção A 
(Agricultura, Pecuária, Produção Florestal, Pesca e Aquicultura):

- 0210-1 - Produção Florestal - Florestas Plantadas;

- 0220-9 - Produção Florestal - Florestas Nativas;

- 0230-6 - Atividade de Apoio à Produção Florestal.

\subsection{Classificação Brasileira de Ocupações (CBO)}

A CBO é a codificação das ocupações do mercado de trabalho brasileiro, sendo uma ferramenta amplamente utilizada na geração de "estatísticas de emprego-desemprego, para o estudo das taxas de natalidade e mortalidade das ocupações, para o planejamento das reconversões e requalificações ocupacionais, na elaboração de currículos, no planejamento da educação profissional, no rastreamento de vagas e nos serviços de intermediação de mão de obra" (MTE, 2002).

Foram selecionadas as classificações vinculadas diretamente às atividades de produção florestal, excluindo os valores nulos, desconhecidos, de atividades administrativas, serviços gerais, comerciais, que estivessem registradas nos CAT.

\subsection{Classificação Internacional de Doenças e Problemas Relacionados à Saúde (CID-10)}

A CID-10 é um sistema de classificação epidemiológico para o registro, análise, interpretação e comparação de dados referentes à morbidade e mortalidade. Apresenta uma respectiva codificação e descrição básica, que serve para fins de avaliação entre diferentes áreas e tempos (Organização Mundial da Saúde - OMS, 2016).

As informações relativas aos agravos e, ou doenças contidas nos CAT são apresentadas nesses códigos. Nesta pesquisa, estes códigos foram agrupados em capítulos, conforme à classificação da OMS.

\subsection{Valor da remuneração}

Os valores de remuneração do segurado foram classificados pelo limite inferior ao valor do salário mínimo no ano do acidente. E também de acordo com o valor do salário mínimo vigente do ano de registro do CAT, nas seguintes categorias: $<1$ salário mínimo $(\mathrm{SM}) ; \geq 1 \mathrm{SM}$ e $<2$ $\mathrm{SM} ; \geq 2 \mathrm{SM} \mathrm{e}<3 \mathrm{SM} ; \geq 3 \mathrm{SM} \mathrm{e}<4 \mathrm{SM} ; \geq 4 \mathrm{SM} \mathrm{e}<5 \mathrm{SM}$; $\geq 5 \mathrm{SM} \mathrm{e}<6 \mathrm{SM}$; e $\geq 6 \mathrm{SM}$.

\section{RESULTADOS}

\subsection{Acidentes por $\mathrm{CNAE}$}

A Produção Florestal de Florestas Plantadas apresentou o maior percentual de CATs registrados, com 59,37\% (434 registros). Seguido da Atividade de Apoio à Produção Florestal com 36,66\% (268 registros) e da Produção Florestal de Florestas Nativas, com uma representação do 3,97\% (29 registros).

\subsection{Acidentes por $\mathbf{C B O}$}

Segundo o tipo de ocupação, o maior percentual foi encontrado para aquelas que procedem de ocupações florestais, sendo 44,7\% (329). Já em 29,1\% dos registros (214) não foi informado a origem, e em 26,2\% (193) foram decorrentes de acidentes em ambientes e ocupações diferentes das desenvolvidas nas atividades florestais.

Quando excluídos os registros sem informação, constatou-se que das 522 comunicações, 63\% (329 registros) são oriundos de atividades florestais. Deste total, 36,8\% dos acidentes aconteceram com trabalhadores de extração florestal. Seguido de operadores de motosserra com 21,3\%, ajudantes de carvoaria com $10,6 \%$, operadores de trator florestal com $6,4 \%$, tratorista agrícola com $6,1 \%$, e $18,8 \%$ correspondente a outras ocupações (Figura 1).

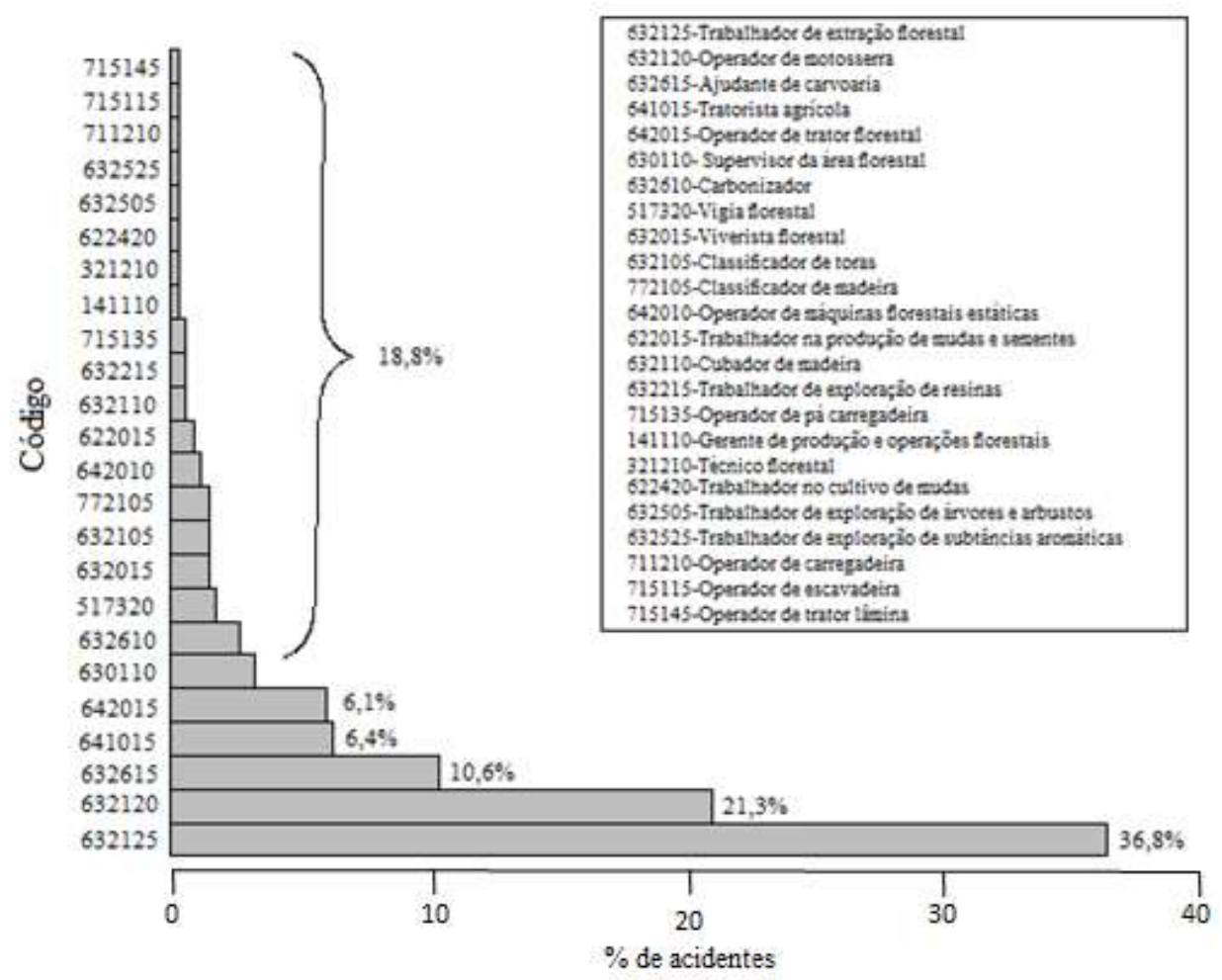

Figura 1. Distribuição dos acidentes de trabalho de acordo com a CBO das atividades florestais no Estado de Minas Gerais, no período de Figure 1. Distribution of accidents at work in accordance with the CBO of forestry activities in the state of Minas Gerais, in the period from 


\subsection{Perfil dos acidentados}

O trabalho florestal é predominante dominado por mão de obra masculina, motivo pelo qual $94,5 \%$ dos acidentes registrados ocorreram em trabalhadores deste gênero. Quanto ao estado civil dos acidentados, $45 \%$ eram casados, $44,1 \%$ solteiros, $6,7 \%$ não identificado, 3,3\% divorciados, $0,6 \%$ viúvos e $0,3 \%$ separados judicialmente.

Quanto a estrutura etária dos acidentados, para a população masculina a maior concentração está na faixa de 41-45 anos com 54 registros (17,4\%), seguido de 36-40 anos com 50 registros $(16,1 \%)$ e, da faixa etária de 31-35 anos com 48 registros $(15,4 \%)$. Já para a população feminina, as faixas de 36-40 anos, 41-45 anos e 46-50 anos, apresentaram a mesma frequência de 4 registros $(22,2 \%)$.

No tocante a questão salarial, $90 \%$ dos trabalhadores acidentados durante o período de estudo ganhavam entre um e menos de dois salários mínimos vigentes. Já 4,3\% ganhavam menos de um salário mínimo, 3,3\% entre dois e menos de três salários mínimos, e 2,4\% mais de três salários mínimos.

\subsection{Características dos acidentes}

Verificou-se que os acidentes foram reportados principalmente entre os dias de segunda e quarta-feira, valor que corresponde a 59,6\%. Desse total, a segunda-feira é o dia com maior percentual $(21,6 \%)$, seguido de terça-feira $(18,5 \%)$, quarta-feira $(19,5 \%)$, quinta-feira $(17,0 \%)$, sextafeira $(15,2 \%)$, sábado $(5,2 \%)$ e no domingo $(3,0 \%)$ dos registros.

Referente ao tipo de acidente, o maior percentual de registro de CAT apresenta que $87,8 \%$ está relacionado a eventos adversos do tipo típico, 11,2\% devido ao trajeto e $1 \%$ a doenças.

\subsection{Parte do corpo atingida}

As lesões nos trabalhadores florestais ocorrem, sobretudo, nos membros superiores (42,6\% dos registros) e inferiores (42,6\% das ocorrências), correspondendo a $85,2 \%$ dos casos (Figura 2).

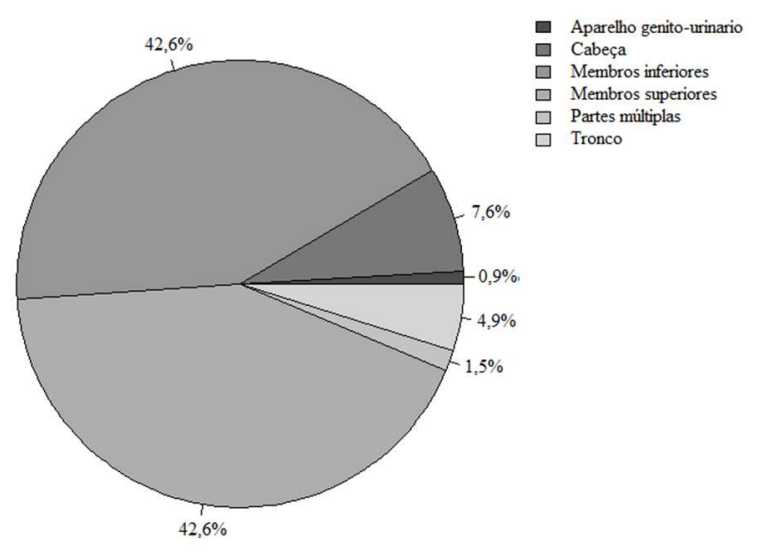

Figura 2. Partes do corpo dos trabalhadores florestais acometida de acidentes no Estado de Minas Gerais, no período de 2011 a 2017. Figure 2. Body parts of forestry workers involved in accidents in the state of Minas Gerais, in the period from 2011 to 2017.

Quanto aos membros superiores, as lesões e ferimentos dos dedos representaram 52,1\%. Seguido de 12,9\% para lesões na mão, sem levar em consideração lesões no punho e nos dedos, e 7,9\% para o ombro.
Em relação aos membros inferiores, o pé (sem considerar os artelhos) foi a parte mais afetada, sendo 35,7\%. Seguido por $17,9 \%$ da perna, considerada entre o tornozelo e a pélvis, e $15 \%$ da articulação do tornozelo.

As lesões nos olhos e em partes múltiplas da face foram as mais frequentes quando a cabeça foi impactada, cada uma com $24 \%$ de ocorrência.

Quanto ao tronco, a área mais afetada foi o dorso, inclusive músculos dorsais, coluna e medula espinhal, correspondendo a 43,8\%. Seguido de $25 \%$ do abdômen, inclusive órgãos internos.

\subsection{Tipos de lesões}

As doenças e problemas relacionados à saúde, produto dos acidentes de trabalho nas atividades florestais, produziram, em $93,9 \%$ dos casos, lesões nas diferentes partes do corpo dos trabalhadores. Em segundo lugar doenças do sistema osteomuscular e tecidos conjuntivo, com 4,6\%. Já o terceiro lugar com $0,6 \%$, correspondeu a doenças do ouvido.

Do total de lesões verificado no período, $49,5 \%$ dos casos foram fraturas, $17,3 \%$ feridas abertas, $9,7 \%$ contusões e esmagamentos com superfície cutânea intacta, 7,0\% distensões e torções e, outros tipos de lesões (16,5\%) (Figura $3)$.

\subsection{Agente e situação geradora do acidente}

O perfil dos acidentes é decorrente das características do setor florestal, situações onde se apresentam a queda de toras de madeiras, ambientes de trabalho em condições desfavoráveis, contato com elementos e ferramentas cortantes, somado a acontecimentos envolvendo veículos em movimento são frequentes, gerando um alto grau de traumatismo nos trabalhadores.

Verificou-se que as situações de impactos dos trabalhadores contra objetos que caem as mais frequentes (12,2\%), seguido de objetos projetados $(10,6 \%)$ e, objetos em movimento $(10,0 \%)$. Os principais agentes foram a madeira (tora, madeira serrada, pranchão, poste, barrote, ripa e produto de madeira), seguido de ambientes de trabalho em condições desfavoráveis, contato com elementos e ferramentas cortantes, somado a acontecimentos envolvendo veículos em movimento (Figuras 4 e 5).

\subsection{Acidentes por municípios}

Dentre os municípios existentes no Estado de Minas Gerais, o de Curvelo foi o que apresentou o maior número de registros de acidentes no período analisado, com 28 CAT. Seguido pelos municípios de João Pinheiro com 24 CAT e Morada Nova de Minas com 21 CAT.

\section{DISCUSSÃO}

Segundo o Instituto Brasileiro de Geografia e Estatística (IBGE, 2016), o Estado de Minas Gerais apresenta uma baixa representatividade na extração de produtos madeireiros e não madeireiros de florestas nativas, em comparação às demais regiões do país. Por sua vez, na produção de florestas plantadas, o Estado apresenta um panorama muito diferente, se destacando na produção de papel e celulose. Também se apresenta no país como o maior produtor de carvão vegetal e madeira para outras finalidades. Sendo assim, já era esperado que a baixa incidência de acidentes de trabalhos na produção de florestas nativas fosse resultado da pouca participação desse tipo de atividade na economia Estadual, 
em contrapartida da produção de florestas plantadas e das atividades de apoio à produção florestal.

Como a CNAE permite o agrupamento de unidades produtivas segundo a atividade econômica principal exercida por pessoa jurídica (empresa). Isto significa que atividades não relacionadas diretamente ao trabalho florestal são registradas como pertencentes a esta categoria. Gerando registros de acidentes advindos de ambientes e ocupações diferentes das desenvolvidas no setor florestal, tais como ocupações comerciais, gerenciais, de transporte, serviços gerais, dentre outras.

Destaca-se também que em um elevado número de registros, a ocupação do trabalhador não foi informada. Provavelmente, essa situação ocorre devido à subnotificação dos acidentes de trabalho, no qual o trabalhador desconhece a necessidade e importância de reportar qualquer incidente ou acidente de trabalho quando da sua ocorrência. Isso decorre, pôr o mesmo considerá-lo trivial ou até mesmo pela repreensão ao preenchimento da CAT por parte das empresas. Esses fatores tendem a gerar registros incompletos ou sem informação referente ao evento adverso ocorrido (BRASILEIRO et al., 2014; NASRALA NETO et al., 2014).

Os resultados encontrados nesta pesquisa, em concordância com Bahia et al. (2010), demonstraram que as faixas etárias mais jovens ( $<25$ anos de idade) e mais velhas ( $>46$ anos de idade) apresentaram os menores índices de acidentes, com os maiores números tendo ocorrido nas faixas etárias de 26 a 35 anos, seguido da faixa de 36 a 45 anos.

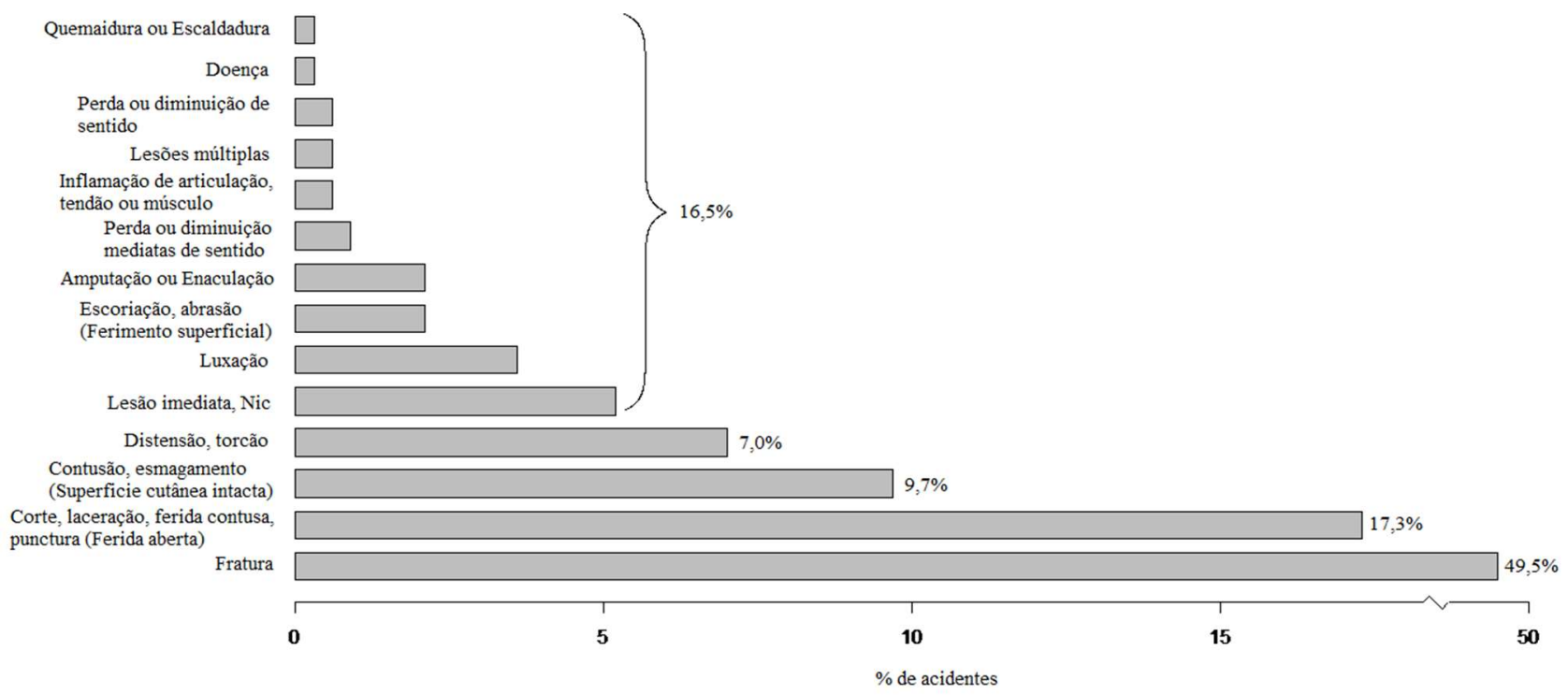

Figura 3. Natureza da lesão de acidentes nos trabalhadores florestais no Estado de Minas Gerais, no período de 2011 a 2017. Figure 3. Type of injury accidents of forestry workers in the state of Minas Gerais, in the period from 2011 to 2017.

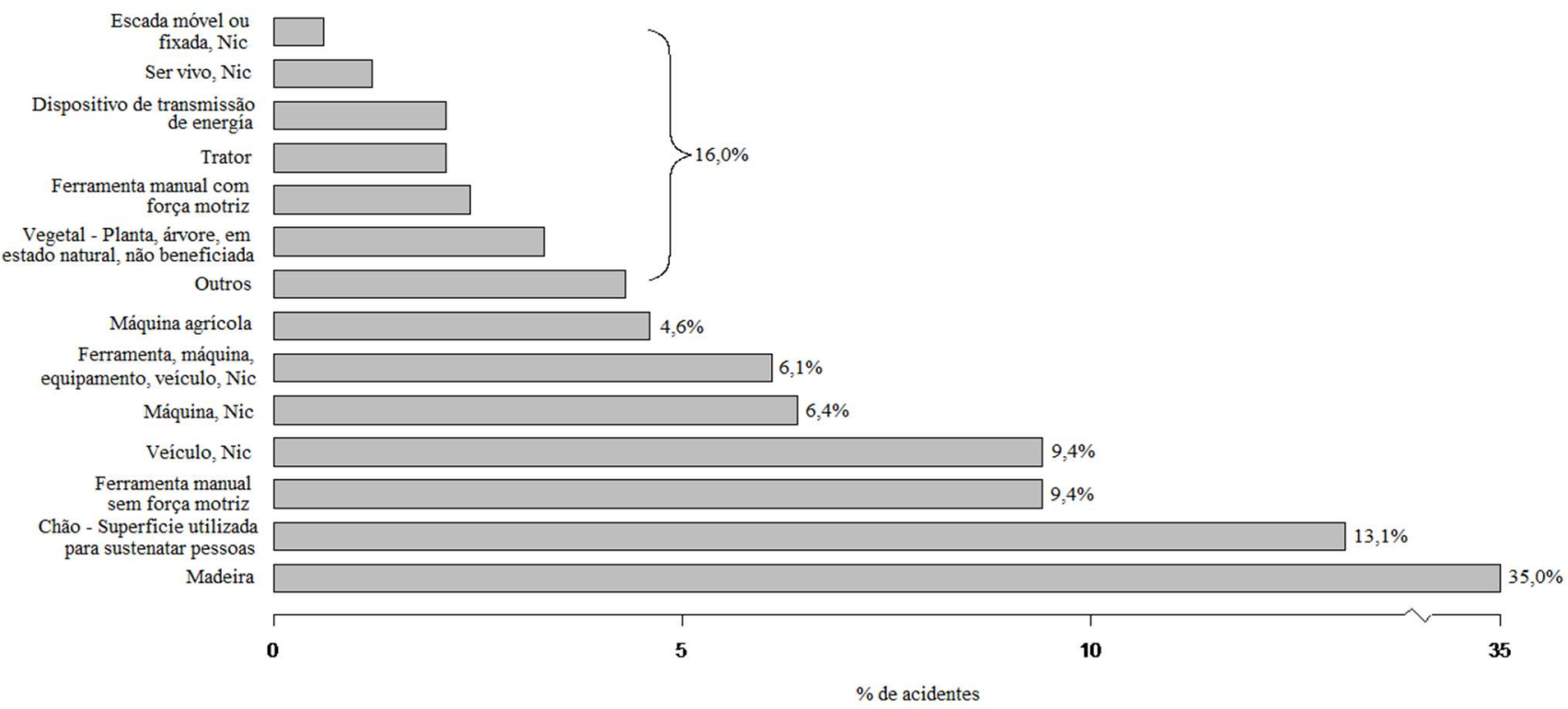

Figura 4. Agente causador dos acidentes nos trabalhadores florestais no Estado de Minas Gerais, no período de 2011 a 2017.

Figure 4. Causative agent of accidents of forestry workers in the state of Minas Gerais, in the period from 2011 to 2017. Source: 


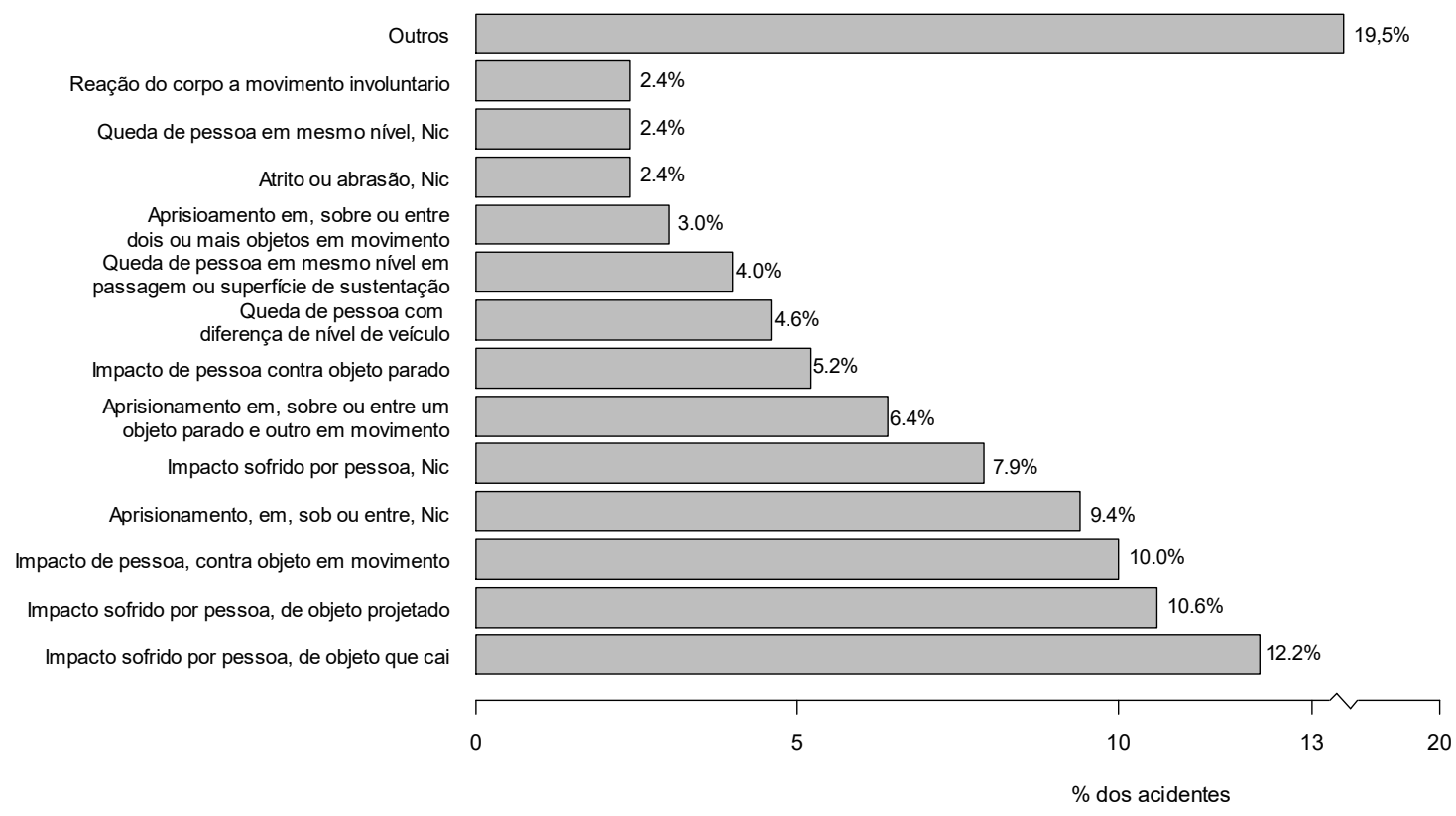

Figura 5. Situação geradora dos acidentes nos trabalhadores florestais no Estado de Minas Gerais, no período de 2011 a 2017.

Figure 5. Generating situation of accidents of forestry workers in the state of Minas Gerais, in the period from 2011 to 2017.

Para Blanch et al. (2009) e o Instituto Nacional do Seguro Social - INSS (2011), altos índices de acidentes neste grupo da população trabalhadora estão relacionados às atividades fisicamente mais pesadas, perigosas ou insalubres, desempenhadas por estes trabalhadores. Outros fatores estão ligados à falta de experiência e ao desconhecimento das normas de segurança, quando comparados aos trabalhadores mais velhos. Em geral, o perfil dos trabalhadores florestais no Estado de Minas Gerais é caracterizado por apresentar mão de obra jovem, com idade média em torno dos 30 anos (LEITE et al., 2012; SIMÕES; ROCHA, 2014; SCHETTINO et al., 2020).

Em outra vertente, tais estudos apontaram que entre $50 \mathrm{e}$ $80 \%$ do total desses trabalhadores, declarou seu estado civil na categoria de casado. Conforme a Organização Internacional do Trabalho - OIT (2005), o setor florestal é caracterizado pela baixa remuneração de seus trabalhadores, tratando-se muitas vezes de um trabalho estacional. Sendo uma vinculação empregatícia não muito clara e com pouca proteção social por parte do Estado, que tem uma ação enfraquecida ou é ausente no sentido de garantir os direitos trabalhistas. Nesse sentido, as famílias dos trabalhadores do setor florestal enfrentam um cenário de dificuldades. Uma vez que a diminuição da capacidade de trabalho ou perda total desta, decorrente de acidentes. Pode gerar a perda parcial ou total dos ganhos financeiros, comprometendo o pagamento por serviços de saúde.

A grande frequência de acidentes de trajeto para trabalhadores florestais pode ser explicada pelo fato destes requererem se movimentar por longas distâncias. Deslocando-se da residência até os locais de trabalho, muitas vezes por estradas de difícil acesso, sob condições climáticas desfavoráveis. Nessas circunstâncias, o trabalhador investe tempo e energia no trajeto, muitas vezes sem horas de sono suficientes para um correto descanso, devido à necessidade de acordar de madrugada para chegar ao local de trabalho. Com isso, se coloca em risco de sofrer acidentes em locais sem facilidades de comunicação, atendimento e pronto socorro (SILVA et al., 2010).
Por outro lado, embora fosse esperado que os acidentes de trabalho reportados apresentassem uma distribuição aleatória em todos os dias da semana. Verificou-se uma concentração das ocorrências nos primeiros dias da semana, confirmando as estatísticas nacionais. Carvalho et al. (2020), ao analisarem todas as ocorrências de acidentes de trabalho no Brasil em um período de sete anos, obtiveram resultados similares aos encontrados neste estudo. Verificando que a maior frequência dos acidentes se concentrava principalmente entre as segundas e quartas-feiras.

A grande frequência de acidentes de trajeto para trabalhadores florestais pode ser explicada pelo fato destes requererem se movimentar por longas distâncias. Deslocando-se da residência até os locais de trabalho, muitas vezes por estradas de difícil acesso, sob condições climáticas desfavoráveis. Nessas circunstâncias, o trabalhador investe tempo e energia no trajeto, muitas vezes sem horas de sono suficientes para um correto descanso, devido à necessidade de acordar de madrugada para chegar ao local de trabalho. Com isso, se coloca em risco de sofrer acidentes em locais sem facilidades de comunicação, atendimento e pronto socorro (SILVA et al., 2010).

Por outro lado, embora fosse esperado que os acidentes de trabalho reportados apresentassem uma distribuição aleatória em todos os dias da semana. Verificou-se uma concentração das ocorrências nos primeiros dias da semana, confirmando as estatísticas nacionais. Carvalho et al. (2020), ao analisarem todas as ocorrências de acidentes de trabalho no Brasil em um período de sete anos, obtiveram resultados similares aos encontrados neste estudo. Verificando que a maior frequência dos acidentes se concentrava principalmente entre as segundas e quartas-feiras.

Como observado, os trabalhadores de extração florestal e os operadores de motosserra apresentam as maiores frequências de ocorrências de acidentes. Isto se explica por estarem em constante contato com os fatores de risco, tais como máquinas e ferramentas com ou sem força motriz. Realizando atividades manuais e semimecanizadas no abate de árvores e manuseio de toras em condições de terreno nem 
sempre favoráveis. Ainda, soma-se ao fato dessas atividades requererem grande esforço físico e adoção de posturas inadequadas, além da manipulação de ferramentas e máquinas pesadas (BAHIA et al., 2010). Esses elementos acabam deixando os trabalhadores expostos a fatores ambientais, tais como: vibração, ruído, gases de combustão e intempéries, e aos ademais do risco de desenvolvimento de distúrbios osteomusculares relacionados ao trabalho (SCHETTINO et al., 2021). Segundo Lopes et al. (2003), no que tange aos trabalhadores florestais, são recorrentes as queixas associadas a problemas de lombalgia, em consequência das atividades desempenhadas.

Por sua vez, as partes do corpo mais acometidas foram os membros superiores e inferiores, também em consonância com as estatísticas nacionais (BAHIA et al., 2010; CARVALHO et al., 2020). Embora nos últimos anos o setor florestal brasileiro venha passando por um processo de mecanização de suas atividades. Ainda existe, uma alta proporção de processos e atividades realizadas de forma manual e semimecanizada. Essas são na maioria das vezes, com a utilização de ferramentas e máquinas manuais mal desenvolvidas e consequentemente inadequadas (motosserra, machado, facão e foice), e também por mão de obra pouco qualificada (SCHETTINO et al., 2017). Esses fatores somados, não exclusivamente, tornam as extremidades do corpo (membros superiores e inferiores) mais susceptíveis de serem atingidos no caso de um evento adverso durante o desenvolvimento das atividades programadas.

Devido à grande proporção de ferimentos e agravos aos trabalhadores envolvidos nas atividades florestais, que estas são consideradas de alto risco. Sendo as empresas florestais consideradas pela classificação nacional de atividades econômicas (CNAE) do Ministério do Trabalho e Emprego (MTE) como grau de risco 4, o mais elevado previsto nessa classificação.

As consequências desses acidentes, em sua maioria, classificam-se como moderados até graves de acordo com o MTE (2010). Principalmente pelo fato dos trabalhadores acidentados requererem afastamento por longos períodos, além de serem submetidos regularmente a intervenções cirúrgicas e procedimentos pós-operatórios. Em virtude das fraturas, decorrentes dos acidentes de trabalho registrados.

Em resultados obtidos por Lopes et al. (2003), 43,3\% dos acidentes geraram afastamentos maiores que 15 dias, e $26,7 \%$ entre 5 a 15 dias. Ressalta-se que os acidentes sofridos podem levar também a perda parcial ou permanente de alguma função orgânica do trabalhador. Contribuindo para a diminuição de sua capacidade laboral ou, até mesmo, a sua incapacitação permanente (SCHETTINO et al., 2021).

A mesorregião Central de Minas Gerais apresentou maior frequência de reportes de acidentes de trabalho, devido concentrar um grande número de empreendimentos florestais e, consequentemente, de trabalhadores nesse setor. O município de Curvelo, situado nessa mesorregião, se destacou ocupando o terceiro lugar em nível nacional e, primeiro no Estado de Minas Gerais em registros de acidentes de trabalho no setor florestal. Estudos mais aprofundados podem indicar o impacto na saúde dos indivíduos e na saúde pública nesses municípios.

\section{CONCLUSÃO}

Os acidentes de trabalho analisados comprometeram principalmente os membros inferiores e superiores dos trabalhadores, com destaque para a cabeça.
As lesões correspondem a quase totalidade dos acometimentos segundo o CID-10, seguido do desenvolvimento de doenças osteomusculares. Fraturas e amputações apresentam elevada ocorrência, gerando regularmente afastamentos permanentes e por longos períodos.

O principal agente causador de acidentes é a madeira já explorada, seguido das condições do terreno, ferramentas manuais sem força motriz (exemplo, machado, facão, etc.) e veículo.

A principal situação geradora de acidente é o impacto sofrido pelo trabalhador seja de objetos que caem ou com objetos projetados e, contra objetos em movimento.

Portanto, o setor florestal expõe os trabalhadores a riscos, cujo resultado origina incapacidades para desempenhar as atividades nele requeridas, complicando e afastando as possibilidades de acesso ao mercado laboral por esses trabalhadores, agravado ainda, por se tratar de uma população considerada vulnerável.

\section{AGRADECIMENTOS}

Ao Programa Estudantes-Convênio de Pós-Graduação PEC-PG, da CAPES/CNPq - Brasil, pela concessão da bolsa de mestrado que possibilitou o desenvolvimento desse trabalho.

\section{REFERÊNCIAS}

ABNT_Associação Brasileira de Normas Técnicas. NBR 14280:2001 - Cadastro de acidentes de trabalho Procedimento e classificação. Rio de Janeiro: ABNT, 2001. 94p.

BAHIA, S. H. A.; DINIZ, C. T.; SOUZA, M. T. S.; XAVIER, S. S. Estudo epidemiológico do setor madeireiro atendido em uma unidade técnica de reabilitação profissional. Revista Paraense de Medicina, Belém, v. 24, n. 1, p. 1-6, 2010. Disponível em: http://files.bvs.br/upload/S/01015907/2010/v24n1/a1951.pdf

BLANCH, A.; TORRELLES, B.; ALUJA, A.; SALINAS, J. A. Age and lost working days as a result of an occupational accident: A study in a shiftwork rotation system. Safety Science, v. 47, n. 10, p. 1359-1363, 2009. DOI: https://doi.org/10.1016/j.ssci.2009.03.001

BRASILEIRO, M. A.; SANTANA, M. C. C. P.; CAMBOIM, E. D. Fatores associados à subnotificação da Perda Auditiva Induzida por Ruído relacionada ao trabalho. Revista Brasileira de Pesquisa em Saúde, Vitória, v. 16, n. 4, p. 54-62, 2014.

CANTO, J. L.; MACHADO, C. C.; SOUZA, A. P.; GARLET, A.; CARVALHO, R. M. M. A.; NOCE, R. Avaliação das condições de segurança do trabalho na colheita e transporte florestal em propriedades rurais fomentadas no Estado do Espírito Santo. Revista Árvore, Viçosa, v. 31, n. 3, p. 513-520. DOI: https://doi.org/10.1590/S0100-67622007000300017

CARVALHO, C. A. S.; SILVA, J. C.; LIMA, J. L. L. P. C.; BRUM, S. S. Saúde e Segurança no Trabalho: um relato dos números de acidentes do trabalho e doenças ocupacionais no Brasil (2012-2018). Brazilian Journal of Business, Curitiba, v. 2, n. 3, p. 2909-2926, 2020. DOI: https://doi.org/10.34140/bjbv2n3-070

EU-OSHA_European Agency for Safety and Health at Work. Occupational safety and health in Europe's 
forestry industry. 2008. 13p. Disponível em: https://osha.europa.eu/en/publications/e-fact-29occupational-safety-and-health-europes-forestryindustry/view

GIL, A. C. Métodos e técnicas de pesquisa social. 6 ed. São Paulo: Editora Atlas, 2008. 200p.

IIDA, I.; GUIMARÃES, L. B. D. Ergonomia: projeto e produção. 3 ed. São Paulo: Edgar Blücher Ltda, 2016. 833p.

INDUSTRIA BRASILEIRA DE ÁRVORES (IBÁ). Relatório 2020. São Paulo: Fundação Getúlio Vargas, 2021. 66 p.

IBGE_Instituto Brasileiro de Geografia e Estatística. Introdução à Classificação Nacional de Atividades Econômicas - CNAE. Versão 2.0, 2007. 525p.

IBGE_Instituto Brasileiro de Geografia e Estatística. Produção Vegetal e da Silvicultura - PEVS. Volume 31, Rio de Janeiro: 2016.

INSS_Instituto Nacional do Seguro Social. Boletim epidemiológico acidentes de trabalho não-fatais: Acidentes de trabalho não-fatais no Brasil 2006 - 2010. 2011. 4p. Disponível em: http://www.ccvisat.ufba.br/wpcontent/uploads/2019/07/Acidentes-de-Trabalhofatais-no-Brasil-2000- $\%$ E2\%80\%03-2010.pdf

LEITE, A. M. P.; SOARES, T. S.; NOGUEIRA, G. S.; PEÑA, S. V. Perfil e qualidade de vida de trabalhadores de colheita florestal. Revista Árvore, Viçosa, v. 36, n. 1, p. 161-168, 2012.2 DOI: http://dx.doi.org/10.1590/S0100-67622012000100017

LOPES, E. S.; ZANLORENZI, E; COUTO, L. C. Análise dos fatores humanos e condições de trabalho no processamento mecânico primário e secundário da madeira. Ciência Florestal, Santa Maria, v. 13, n. 2, p. 177-183, 2003.2 DOI: http://dx.doi.org/10.5902/198050981754

MTE_Ministério do Trabalho e Emprego. Classificação Brasileira de Ocupações 2002. Livro 1, 2002. 648p.

MTE_Ministério do Trabalho e Emprego. Guia de análise Acidentes de Trabalho. São Paulo: 2010. 78p.

MPT-OIT_Ministério Público do Trabalho; Organização Internacional do Trabalho. Observatório Digital de Saúde e Segurança no Trabalho (MPT-OIT): 2017. Disponível em: <http://observatoriosst.mpt.mp.br>. Acesso em: 09 jul. 2018.

NASRALA NETO, E.; BITTENCOURT, W. S.; NASRALA, M. L. S.; SOUSA, F. P.; RODER, I. B. A Influência do Nexo Técnico Epidemiológico Previdenciário Sobre as Notificações de LER/DORT no INSS. UNOPAR Cientifíca - Ciências Biológicas e da Saúde, Londrina, v. 16, n. 3, p. 209-212, 2014. DOI: https://doi.org/10.17921/2447-8938.2014v16n3p\%25p

OIT_Organização Internacional do Trabalho. Directrices sobre la inspección del trabajo en la silvicultura. Genebra: OIT, 2005. 63p. Disponível em: https://www.ilo.org/wcmsp5/groups/public/--ed_protect/---protrav/---

safework/documents/normativeinstrument/wcms_112 510.pdf

OMS_Organização Mundial da Saúde. International statistical classification of diseases and related health problems - 10th revision. 5 ed. Genebra: World Health Organization, 2016. 2131p.
SCHETTINO, S.; MINETTE, L. J.; BERMUDES, W. L.; CAÇADOR, S. S.; SOUZA, A. P. Ergonomic study of timber manual loading in forestry fomentation áreas. Nativa, Sinop, v. 5, n. 2, p. 145-150, 2017. DOI: https://doi.org/ 10.5935/2318-7670.v05n02a11

SCHETTINO, S.; GUIMARÃES, N. V.; SILVA, D. L.; SOUZA, C. L. L.; MINETTE, L. J.; PAULA JUNIOR, J. D.; SCHETTINO, C. F. Relação entre a ocorrência de acidentes de trabalho e a baixa escolaridade dos trabalhadores no setor florestal. Brazilian Journal of Development, Curitiba, v. 6, n. 4, p. 22567-22589, 2020. DOI: https://doi.org/10.34117/bjdv6n4-427

SCHETTINO, S.; MINETTE, L. J.; LIMA, R. C. A.; NASCIMENTO, G. S. P.; CAÇADOR, S. S.; VIEIRA, M. P. L. Forest harvesting in rural properties: Risks and worsening to the worker's health under the ergonomics approach. International Journal of Industrial Ergonomics, v. 82, não paginado, 2021. DOI: https://doi.org/10.1016/j.ergon.2021.103087

SILVA, E. P.; COTTA, R. M. M.; SOUZA, A. P.; MINETTE, L. J.; VIEIRA, H. A. N. F. Diagnóstico das condições de saúde de trabalhadores envolvidos na atividade em extração manual de madeira. Revista Árvore, Viçosa, v. 34, n. 3, p. 561-565, 2010.

SIMÕES, M. R. L.; ROCHA, A. M. Absenteísmo-doença entre trabalhadores de uma empresa florestal no Estado de Minas Gerais, Brasil. Revista Brasileira de Saúde Ocupacional, São Paulo, v. 39, n 129, p. 17-25, 2014. DOI: https://doi.org/10.1590/0303-7657000061112

SUCHOMEL, J.; BELANOVÁ, K.; STOLLMANN, V. Analysis of occupational diseases occurring in Forestry and Wood Processing Industry in Slovakia. Drvna Industrija, Zagreb, v. 62, n. 3, p. 219-228, 2011. DOI: https://doi.org/10.5552/drind.2011.1104 